\title{
Effect of cold work and aging on mechanical properties of a copper bearing HSLA-100 steel
}

\author{
SANJAY PANWAR ${ }^{\dagger}$, D B GOEL* and O P PANDEY ${ }^{\dagger}$ \\ Department of Metallurgical and Materials Engineering, Indian Institute of Technology Roorkee, Roorkee 247667 , \\ India \\ ${ }^{\dagger}$ School of Physics and Materials Science, Thapar Institute of Engineering \& Technology, Patiala 147 004, India
}

MS received 5 March 2005

\begin{abstract}
Influence of cold working and aging on the mechanical properties of a Cu-bearing HSLA-100 steel has been studied. The steel was given solution treatment at $1000^{\circ} \mathrm{C}$, followed by cold rolling to 25,50 and 80 pct deformations and aging at $600^{\circ} \mathrm{C}$ for various durations. Substantial improvement in hardness and UTS was observed in the peak aged condition of various treatments, but at the expense of ductility and impactenergy. Extensive scanning electron microscopic studies carried out on impact and tensile fracture surfaces suggest that poor impact energy and low ductility in peak aged condition could be associated with inhomogeneous deformation caused by the existence of coherent precipitates. Other parameters adversely affecting toughness and ductility in various stages of cold work and aging may include high stress concentration at high density dislocation network and dislocation-precipitate interface. Overaging in various treatments resulted in higher impact energy and ductility, presumably due to existence of incoherent precipitates and reduction in stress concentration at dislocation cell boundaries. It is observed that a good combination of high hardness and UTS with high impact energy and ductility could be obtained by a treatment suitable to cause coexistence of coherent and incoherent precipitates.
\end{abstract}

Keywords. Striations; microvoids; dislocation network; peak aging; over aging.

\section{Introduction}

In recent years substantial emphasis has been laid on the development of various grades of high-strength low-alloy (HSLA) steels. Various attempts have been made to improve the toughness of this structural material by the addition of alloying elements (Kim et al 2001), special heat treatments (Kim et al 1983; Ingelbriech 1985; Kim et al 2001) as well as by thermomechanical treatments along with suitable modifications in production methods (Furugimi et al 1986; Uhashi 1986; Suenaga et al 1987). The basic aim of all these modifications was to reduce impurity elements or non-metallic inclusions, which are harmful for achieving high toughness. A need is also felt to develop steels with very high yield strength for making many critical components of naval and engineering applications that are subjected to complex dynamic loading (Czyryca 1993). This is possible by either varying the chemical composition of the steel or by changing the processing routes. The role of alloying additions and processing parameters has been studied extensively (Okatsu et al 1997; Vasseur et al 1997; Kostic et al 1998). Since copper is added to HSLA steels to cause precipitation

\footnotetext{
*Author for correspondence (dbgmtfmt@iitr.ernet.in)
}

strengthening, Cu-bearing HSLA steels have attracted attention of researchers in the recent past (SkoufariThemistou et al 1999; Dhua et al 2001; Ghosh et al 2003, 2004; Panwar et al 2003; Mao et al 2004; Nakada et al 2004). The phenomenon of precipitation in these steels has not yet been fully exploited for development of high tensile and high impact properties. It has been observed for various alloy systems that strengthening effects are associated with poor impact strength. In Cu-bearing HSLA steels, such a study has not yet been conducted. In this paper mechanical properties developed as a result of strain induced aging of a Cu-bearing HSLA-100 steel have been described. Mechanical properties have been studied for various stages of aging with and without prior mechanical working.

\section{Experimental}

The HSLA steel investigated in this study was supplied by the Naval Research Laboratory, Washington DC, USA, in the form of a plate of thickness $51 \mathrm{~mm}$ and size $300 \times$ $200 \mathrm{~mm}$. The chemical composition (wt. pct) of the steel was: $\mathrm{C}-0 \cdot 04, \mathrm{Mn}-0 \cdot 86, \mathrm{P}-0 \cdot 004, \mathrm{~S}-0.002, \mathrm{Si}-0 \cdot 27, \mathrm{Cu}-1 \cdot 58$, $\mathrm{Ni}-3 \cdot 55, \mathrm{Cr}-0 \cdot 57, \mathrm{Mo}-0 \cdot 60, \mathrm{Al}-0 \cdot 032, \mathrm{Nb}-0 \cdot 03$. Bars of appropriate dimensions were taken from the as-received 
steel plate for various heat treatments. The various treatments were designated as follows:

OQ: Solution treatment at $1000^{\circ} \mathrm{C}$ for $180 \mathrm{~min}$ followed by oil quenching.

OQA: OQ treatment, followed by aging at $500^{\circ} \mathrm{C}$ for various times ranging from $1-6000 \mathrm{~min}$, followed by water quenching.

C25A: OQ treatment, followed by cold rolling to $25 \mathrm{pct}$, followed by aging at $600^{\circ} \mathrm{C}$ for various times ranging from 1-1500 min.

C50A: OQ treatment, followed by cold rolling to 50 pct, followed by aging at $600^{\circ} \mathrm{C}$ for various times ranging from 1-1500 min.

C80A: OQ treatment, followed by cold rolling to $80 \mathrm{pct}$, followed by aging at $600^{\circ} \mathrm{C}$ for various times ranging from 1-1500 min.

TC25A: OQ treatment, followed by tempering at $700^{\circ} \mathrm{C}$ for $120 \mathrm{~min}$, followed by cold rolling to $25 \mathrm{pct}$, followed by aging at $500^{\circ} \mathrm{C}$ for various times ranging from 1$3000 \mathrm{~min}$.

The peak aged (PA) condition referred to the stage of peak observed in hardness-aging curves. Over aged (OA) condition referred to aging for $1500 \mathrm{~min}$ for C25A, C50A and $\mathrm{C} 80 \mathrm{~A}$ treatments, $3000 \mathrm{~min}$ for TC25A treatment and $6000 \mathrm{~min}$ for OQA treatment.

Hardness (Vickers) measurements were made on test specimens by employing a $30 \mathrm{~kg}$ load. Detailed examinations were conducted on oil quenched (OQ), cold worked $(\mathrm{CW})$, peak aged (PA) and over aged (OA) conditions in various treatments. Tensile tests as per ASTM E8M standard were performed on Hounsfield H25K-S materials testing machine with a crosshead speed of $1 \mathrm{~mm} / \mathrm{min}$ at room temperature. Charpy V-notch specimens were prepared as per ASTM E23 standard and tested on impact testing machine at room temperature. Scanning electron microscopic (SEM) studies were conducted on the fracture surfaces of tensile and impact specimens at $15 \mathrm{kV}$ with LEO 435 VP scanning electron microscope.

\section{Results}

\subsection{Mechanical properties}

Figure 1 shows the variation of hardness with aging time after various treatments. In all aging treatments hardness increases, attains a peak value and then decreases regularly with increasing aging time. It is observed that cold working prior to aging reduces the time to reach peak hardness. The peak hardness occurs after $120 \mathrm{~min}$ in OQA, after $5 \mathrm{~min}$ in $\mathrm{C} 25 \mathrm{~A}$ and $\mathrm{C} 80 \mathrm{~A}$ treatments, after $15 \mathrm{~min}$ in C50A treatment and after $10 \mathrm{~min}$ in TC25A treatment. It is also observed that age hardening response increases with the degree of cold work. Accordingly, C80A treatment gives maximum value of hardness in CW (331 VHN) and
PA (371 VHN) conditions as compared to the corresponding values for other treatments. Figure 2 gives the mechanical properties of steel after various treatments. It is seen that in general, high hardness and UTS in PA conditions are accompanied by low values of ductility (pct elongation) and impact energy, which may restrict the use of this steel in PA condition. Overaging in all treatments causes improvement in ductility and impact energy. In the TC25A treatment, peak aging results in high hardness (332 VHN) and UTS (1040 MPa) while maintaining significant ductility (13.9 pct elongation) and impact energy (187.9 J).

\subsection{Scanning electron microscopy}

3.2a Charpy V-notch (CVN) specimens: The scanning electron micrographs of fracture surfaces after various treatments are shown in figure 3. The SEM study of impact fracture surfaces shows that fracture occurs by formation of dimples, microvoids and cracks. In case of high impact energy, the fracture is normally accompanied by formation of fine network of dimples and fine microvoids, whereas low impact energy is revealed by (i) formation of quasi cleavage and faceted patterns, (ii) coarse dimple networks, (iii) coarse microvoids and (iv) fine cracks.

Figure 3(a) reveals the formation of networks of fine ductile dimples as a result of OQ treatment, which results in significantly high impact energy $(227.7 \mathrm{~J})$. Cold working prior to aging results in lowering of impact energy, which causes formation of sheared dimples and large microvoids. It is observed that high degree of cold work leads to formation of quasi cleavage patterns and cracks. Such patterns indicate poor resistance to cleavage fracture. Figure 3(b) shows SEM micrograph of impact fracture surface after cold working in C50A treatment, which

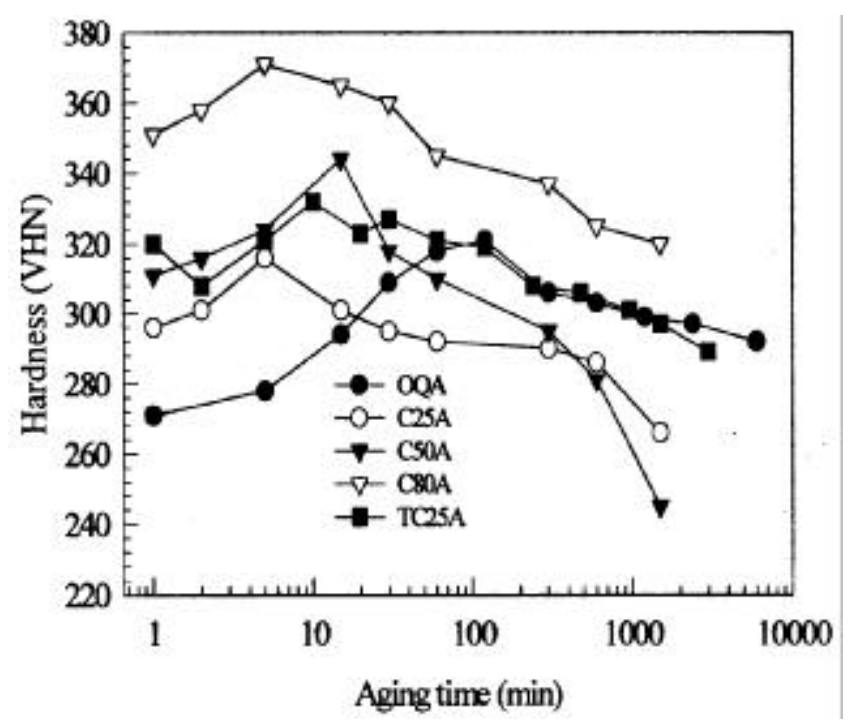

Figure 1. Variation of hardness with aging time. 
results in an impact energy value of $165 \cdot 7 \mathrm{~J}$. It shows a predominantly quasi cleavage pattern, which marks a low impact energy. Peak aging generally deteriorates the impact energy substantially, which is manifested by coarse and faceted networks of dimples together with coarse microvoids and quasi cleavage appearance.

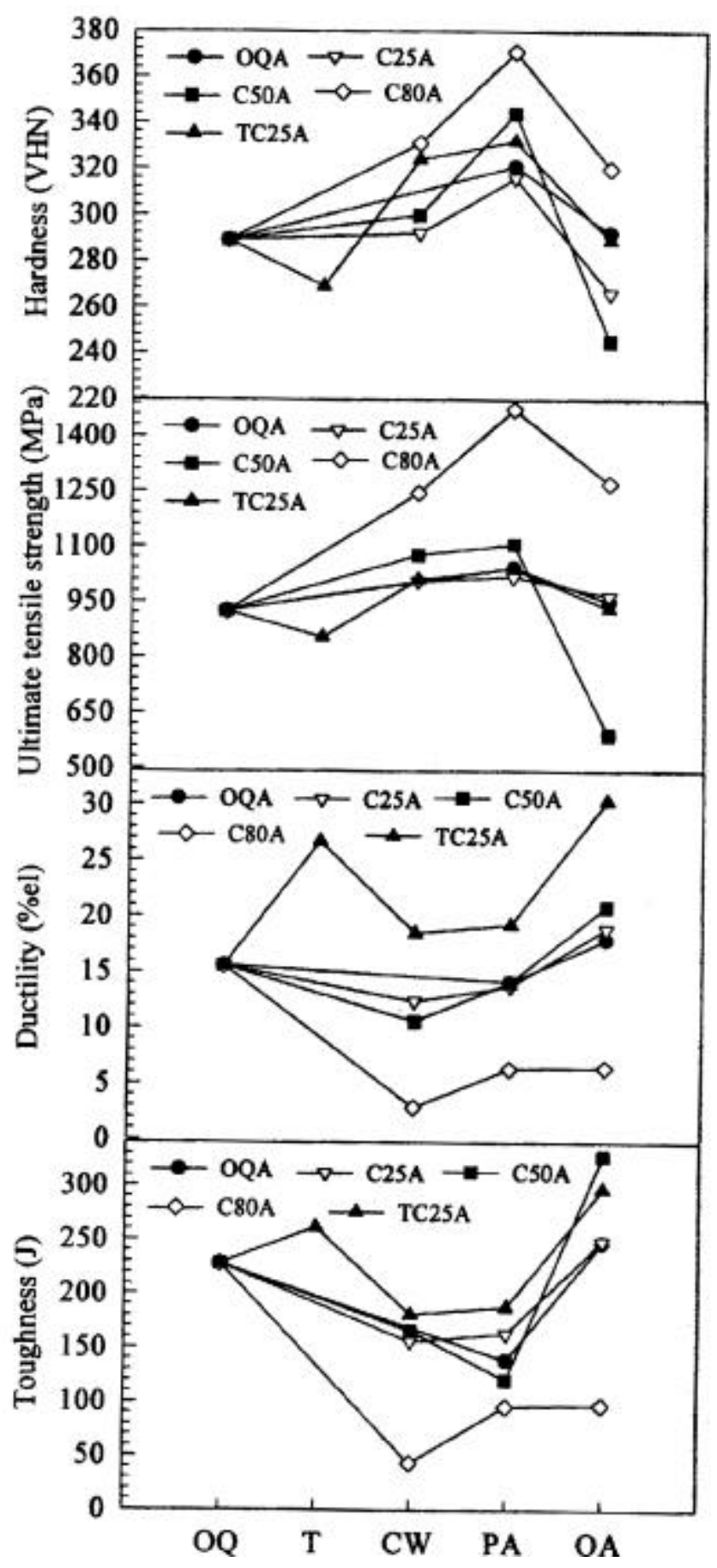

Figure 2. Mechanical properties in various conditions (OQ: oil quenched, T: tempered, CW: cold worked, PA: peak aged and OA: over aged).
Figure 3(c) gives a SEM micrograph of impact fracture surface in the PA condition in C80A treatment. The extremely low impact energy $(96 \mathrm{~J})$ resulting from this treatment is reflected by the existence of large micro cracks and a quasi cleavage appearance of the fracture surface. Overaging causes significant improvement in impact energy. The high impact values in OA conditions are manifested by the coexistence of fine dimple networks and relatively large concentration of precipitate nucleated microvoids. Highest impact energy $(327.5 \mathrm{~J})$ is observed in OA condition of C50A treatment. As seen in figure $3(\mathrm{~d})$, the SEM micrograph of C50A treated specimen in OA condition exhibits very fine network of ductile dimples and fine microvoids, which are nucleated at locations of fine precipitate particles.

3.2b Tensile specimens: The SEM study of tensile fracture surfaces exhibits features, which have good correlation with the observed ductility after various treatments. SEM study of peripheral/outer zones in the fracture surfaces appears helpful in understanding the mechanism of crack initiation in tensile tests. Striations in all the tensile specimens are observed at the circumference of the fractured neck as a result of the shearing of the specimen. The study shows that the striation patterns are appreciably influenced as a result of changes in ductility. Cracks and micro cavities are formed at junctions of such striations as marked by arrows in figure 4 . Low ductility $(6 \cdot 3 \mathrm{pct})$ as observed in PA condition of C80A treatment is reflected by a quasi cleavage appearance of the tensile fracture surface as seen in figure 4(c). This SEM micrograph also shows that existence of precipitate particles assists in crack/void nucleation at striation-particle interfaces. In the treatments resulting in extremely high ductility, the striations are wavy and assume the shape of ductile dimples as seen in the SEM fractograph of C50A treated specimen in OA condition (figure 4d), which exhibits high elongation of $20 \cdot 8$ pct.

\section{Discussion}

Although two precipitation hardening elements $(\mathrm{Cu}$ and $\mathrm{Nb}$ ) are present in this steel, the occurrence of single age hardening peaks suggests that the precipitation hardening is primarily due to the presence of copper. Cold working of $\mathrm{Fe}-\mathrm{Cu}$ alloys and $\mathrm{Cu}$-containing steels enhances the precipitation of copper (Wilson 1968; Soeno 1970; Duggan and Roberts 1973), which increases the peak hardness and reduces the time to reach it. The peak hardness increases with increasing degree of cold work. At various degrees of cold work the positions of hardening peaks may change due to competition between the recrystallization and aging processes.

The enhancement in hardness and UTS in PA condition is accompanied by drastic fall in ductility and impact 
toughness as seen in figure 2 . In case of C80A treatment, the high values of hardness (371 VHN) and UTS (1473 MPa) are accompanied by low ductility ( $6 \cdot 3$ pct elongation) and low impact energy $(96 \mathrm{~J})$. Overaging in all treatments results in improved ductility and impact energy, although at the cost of hardness and UTS. This kind of behaviour poses a challenge for the effective use of this steel in PA condition. Establishing actual cause of poor ductility and impact energy in $\mathrm{PA}$ condition has been a challenging task for various researchers (Soeno 1970; SkoufariThemistou et al 1999; Dhua et al 2001; Ghosh et al 2004; Mao et al 2004; Nakada et al 2004). According to their investigations, high strength materials are hardened by the formation of coherent precipitates. These coherent precipitates are easily cut by moving dislocations, and when sheared once, slip deformation is concentrated in a particular slip plane. This leads to inhomogeneous deformation, early crack initiation and poorer ductility and toughness. In the OA condition, the strengthening precipitates are incoherent and can be bypassed by dislocations; homogeneous deformation takes place, which leads to increasing toughness with delayed crack nucleation. Skoufari-Themistou et al (1999) observed in a $2 \mathrm{wt}$ pct
$\mathrm{Cu}$-bearing steel that peak aging increases the impact transition temperature (ITT), thereby reducing the impact toughness. However, over aging reduces ITT and gives improved impact properties. The remarkable improvement in impact behaviour in OA condition is most probably due to the presence of a large volume fraction of the soft copper precipitates. Skoufari-Themistou et al (1999) also reported that the incoherent precipitates deform readily, rather than acting as impenetrable barrier to the dislocation motion. This ability to deform minimizes stress concentrations occurring as a result of pile ups, which could delay the crack nucleation. In view of the different roles of coherent and incoherent precipitates, Hamano (1993) studied the impact of coexistence of coherent and incoherent precipitates on ductility and impact behaviour of high strength steels. He observed that coexistence of coherent and incoherent precipitates increases homogeneous deformation, thus preventing localization of strain concentration and early cleavage. Thus the combined effect of coherent precipitates in strengthening the matrix and of incoherent precipitates in promoting homogeneous deformation can be expected to increase both hardness and toughness of the material. In this study, the TC25A
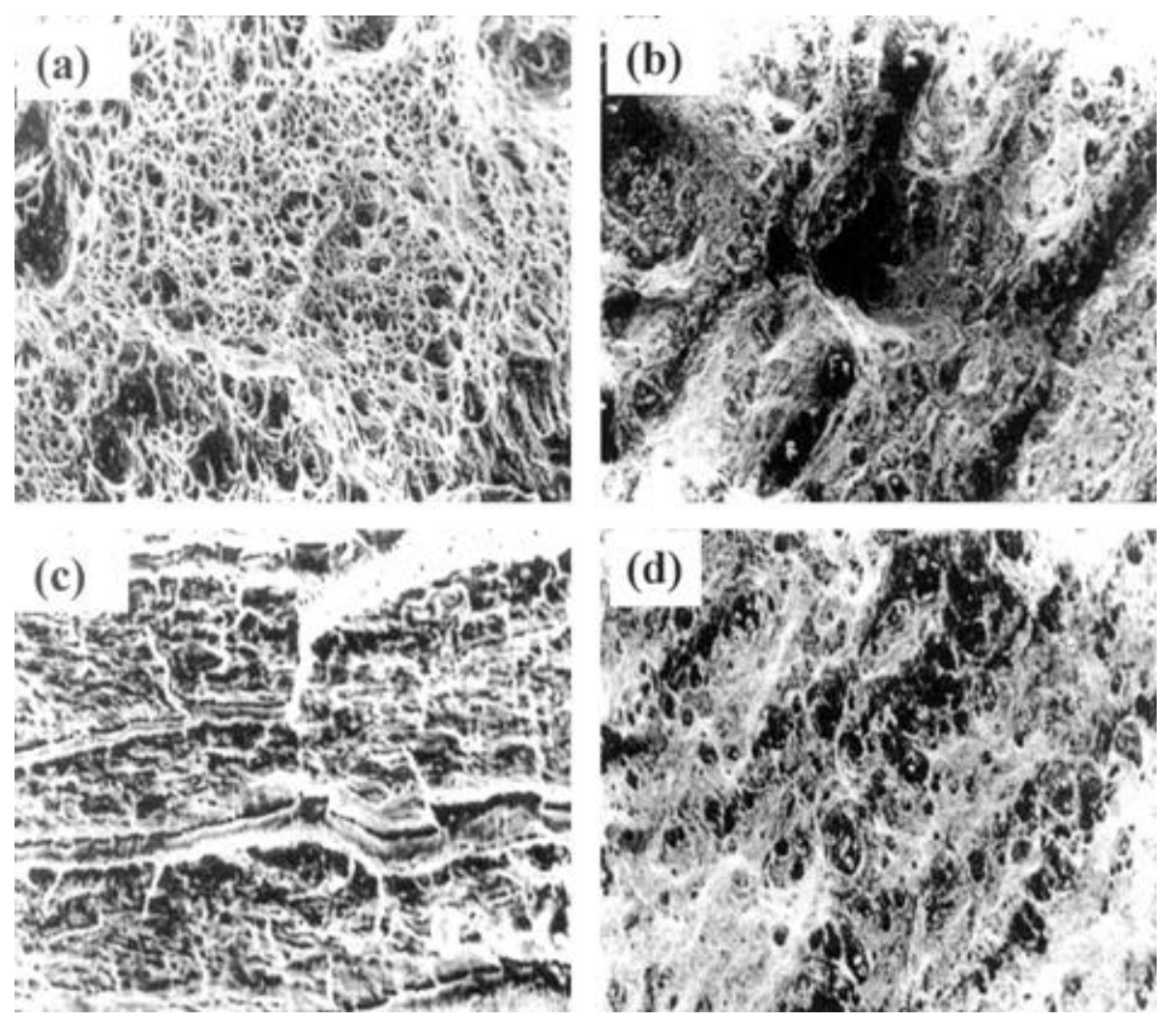

Figure 3. SEM micrographs of impact fracture surfaces showing (a) networks of fine ductile dimples in OQ condition $(1.25 \mathrm{kX})$, (b) predominantly quasi cleavage pattern and large microvoids after 50 pct cold work in C50A treatment $(1.25 \mathrm{kX}),(\mathbf{c})$ quasi cleavage and micro cracks after peak aging in C80A treatment $(5 \mathrm{kX})$ and (d) networks of fine ductile dimples and precipitate nucleated microvoids after overaging in C50A treatment (500X). 
treatment was given with the objective of studying the combined influence of coherent and incoherent precipitates on mechanical properties of the HSLA steel. Tempering at $700^{\circ} \mathrm{C}$ for $120 \mathrm{~min}$ was carried out to produce incoherent precipitates and further 25 pct cold work followed by aging at $500^{\circ} \mathrm{C}$ was carried out to produce incoherent precipitates. Thus in agreement with the observations of Hamano (1993), it is seen from figure 2 that a fairly good combination of high strength, toughness and ductility is obtained in PA condition in the TC25A treatment. It is therefore necessary to design thermomechanical aging treatments in Cu-bearing HSLA steels, which may cause coexistence of coherent and incoherent precipitates in suitable proportions for desired levels of strength, ductility and toughness.

The study of precipitation in age hardenable $\mathrm{Cu}$-containing HSLA steels is extremely difficult. Extensive transmission electron microscopic study on this steel has been reported by the authors in a recent paper (Panwar et al 2003). Hardness peaks on aging are usually obtained when the precipitates are extremely small, e.g. $<10 \mathrm{~nm}$. To study the early stages of precipitation with conven- tional techniques is usually difficult or impossible, because the precipitates remain unresolved in the electron microscope until the alloy has passed its peak strength. Hornbogen and Glenn (1960) indicated that lack of precipitate contrast in the electron micrographs is due to the similarity of scattering factors of iron and copper and negligible strains produced by precipitates because of small difference in the atomic radii of the two species. Miglin et al (1983) also reported that the coherent, $\mathrm{Cu}-\mathrm{Fe}$ precipitates, which form initially during aging of a $\mathrm{Cu}$ bearing high strength steel, lack a strain field of sufficient intensity and are not visible in the electron microscope. Oil quenching after austenitization produces laths of martensite with high dislocation density. Cold working involved in various treatments in this study increases further the density of dislocations (Panwar et al 2003). The high dislocation density together with lack of strain contrast makes the study of early stages of precipitation in Cu-bearing HSLA steels by electron microscopy almost impossible. Therefore, the coexistence of coherent and incoherent precipitates is purely speculative in various studies (Hamano 1993; Dhua et al 2001; Panwar et al
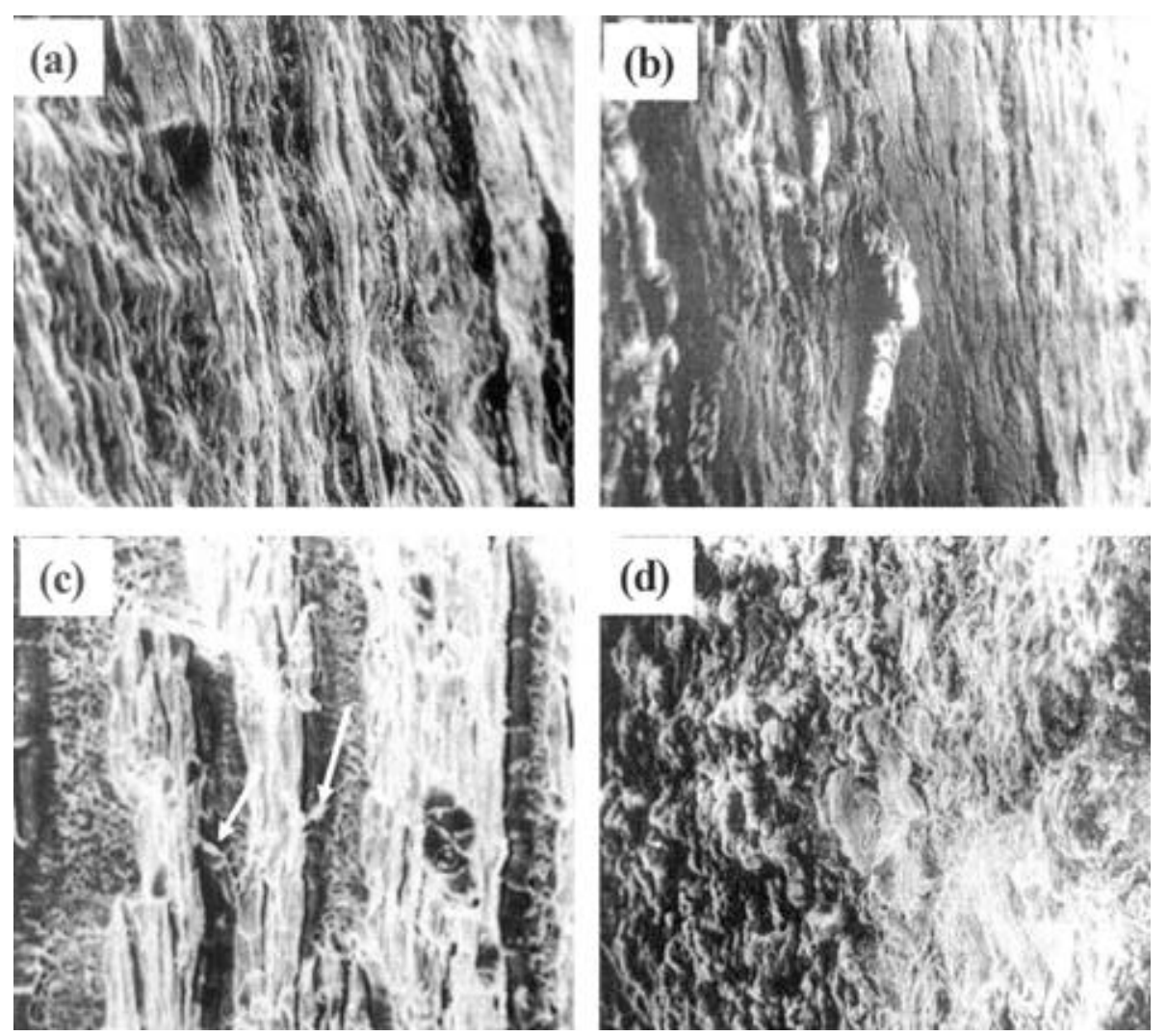

Figure 4. SEM micrographs of tensile fracture surfaces showing (a) closely spaced striations and microvoids after peak aging in OQA treatment $(1.00 \mathrm{kX})$, (b) large cavities and cracks after 50 pct cold work in C50A treatment (500X), (c) quasi cleavage pattern and formation of cracks at precipitate-striation junctions (marked by arrows) after peak aging in C80A treatment $(6.25 \mathrm{kX})$ and $(\mathbf{d})$ wavy network of striations and ductile dimples after overaging in C50A treatment (500X). 
2003). In this study also, to believe that TC25A treatment in the PA condition will cause a combination of coherent and incoherent precipitates is only based on assumption. The SEM study of impact fracture surfaces supports the impact values obtained after various treatments. The high impact energy as observed in OQ treatment $(227.8 \mathrm{~J})$ and in OA condition of C50A treatment $(327.5 \mathrm{~J})$ is characterized by a network of ductile dimples in the SEM micrographs as seen in figure $3(\mathrm{a}, \mathrm{d})$. As revealed in figure $3(\mathrm{~d})$, in the OA condition, microvoids are observed to be nucleated at fine precipitate locations. Low impact energy in CW condition is manifested by existence of large microvoids and cracks together with a quasi cleavage appearance (figure $3 \mathrm{~b}$ ). The size of microvoids is larger and the quasi cleavage appearance of fracture surface becomes more distinct at extremely low impact value $(96 \mathrm{~J})$ as observed in SEM micrograph of C80A in PA condition (figure 3c). In the SEM study of tensile fracture surfaces, it is observed that low ductility is characterized by formation of cracks and cavities at high density striations, which are formed as a result of high stress concentration at dislocation networks. As seen in figure 4, the low ductility (6.3 pct elongation) in PA condition of $\mathrm{C} 80 \mathrm{~A}$ is due to formation of large size of such voids and cracks (figure $4 c$ ). Such voids and cracks are not only due to high stress concentration at striation junctions, but are also assisted by precipitate particles. Homogeneous deformation leading to high ductility is characterized by finely distributed striations, which even assume the shape of ductile dimples as seen in figure $4(d)$.

A comprehensive analysis of mechanical properties resulting from various thermomechanical aging treatments in this study poses a very complex problem. The various parameters, which may affect such properties, may include nature of precipitates, dislocation networks, dislocation-precipitate tangles and martensite lath networks. Extremely low ductility and impact energy in various $\mathrm{CW}$ conditions are apparently due to high stress concentrations at boundaries of dislocation cells and martensite laths, which lead to early nucleation of micro cavities and cracks, as seen in figures 3(b) and 4(b). As cold worked material is subjected to aging, the processes of recrystallization and precipitation occur simultaneously and therefore, the mechanical properties in the PA and OA conditions are due to combined effect of recovery/recrystallization and precipitation. It is for this reason, that only in C50A treatment there is fall in impact energy when this material is peak aged after cold deformation; whereas in all other treatments the impact energy tends to improve on peak aging from the cold work state. Therefore, the interaction between the processes of precipitation and recrystallization on aging is also of importance in deciding the resultant strength and toughness behaviour. The extraordinary improvement in the impact toughness on overaging may even be as a result of transformation of martensite to polygonal ferrite. Ghosh et al (2004) in a recent study on a $\mathrm{Cu}$-bearing steel observed that transformation of martensite into fine polygonal ferrite results in improved impact properties.

\section{Conclusions}

(I) Cold working and subsequent aging enhance the peak hardness and UTS, but significantly deteriorate the ductility and impact energy.

(II) Treatments causing coexistence of coherent and incoherent precipitates may provide combination of high hardness, high UTS together with high ductility and impact energy.

(III) Poor impact energy is a consequence of (i) inhomogeneous deformation at coherent particle sites and (ii) high stress concentrations at dislocation-precipitate junctions and dislocation cell walls.

(IV) Low tensile ductility is due to high stress intensity at deformation striations and precipitate-matrix interface.

(V) Interaction between recrystallization and precipitation and phase transformation during thermomechanical aging treatments may also influence mechanical properties, which needs to be exhaustively studied.

\section{Acknowledgement}

The steel used in this investigation was received from the Naval Research Laboratory, Washington (USA) under an Indo-US collaborative programme.

\section{References}

Czyryca E J 1993 Key engineering materials (Aedermannsdorf, Switzerland: Trans. Tech. Publication) 84-85 p. 491

Dhua S K, Mukerjee D and Sarma D S 2001 Metall. Mater. Trans. A32 2259

Duggan B J and Roberts W T 1973 Met. Sci. J. 7133

Furugimi O, Nkano Y, Ueda S and Tanaka T 1986 J. Iron Steel Inst. Jpn. (Tetsu to-Hagane) 721621

Ghosh A, Das S, Chatterjee S, Mishra B and Ramachandra Rao P 2003 Mater. Sci. Eng. A348 299

Ghosh A, Mishra B, Das S and Chatterjee S 2004 Mater. Sci. Eng. A374 43

Hamano R 1993 Metall. Trans. A24 127

Hornbogen E and Glenn R C 1960 TMS-AIME 2081064

Ingelbriech D 1985 J. Mater. Sci. 213034

Kim J I, Syn C K and Morris J W Jr 1983 Metall. Trans. A14 93

Kim S J, Lee C G, Choi I and Lee S 2001 Metall. Mater. Trans. A32 505

Kostic M M, Collins L E, Kapoor A and O'hara R D 1998 Proc. int. pipelines conf. (NewYork: ASME) 1 p. 665

Mao W, Ren H and Yu Y 2004 Z. Metallkd. 9557

Miglin M T, Hirth J P and Rosenfield A R 1983 Metall. Trans. A14 2055

Nakada N, Syarif J, Tsuchiyama T and Takaki S 2004 Mater. Sci. Eng. 374137 
Okatsu M, Kawabata F and Amano K 1997 Proc. OMAE, ASME New York 3 p. 119

Panwar S, Goel D B, Pandey O P and Prasad K S 2003 Bull. Mater. Sci. 26441

Skoufari-Themistou L, Crowther D N and Mintz B 1999 Mater. Sci. Technol. 151069

Soeno K 1970 Trans. JIM 11185
Suenaga H, Fukai H, Takamatsu H and Ouchi C 1987 J. Iron Steel Inst. Jpn. (Tetsu-to-Hagane) $73 \mathrm{~S} 1510$

Uhashi N 1986 J. Iron Steel Inst. Jpn. (Tetsu-to-Hagane) 72747

Vasseur E, Di Fant M, Danielou A and Streisselberger A 1997 Proc. mechanical working and steel processing conf. (Warrendale, PA: ISS-AIME) p. 503

Wilson E A 1968 JISI 206164 